Archives de sciences sociales des religions

$168 \mid 2014$

Bulletin Bibliographique

\title{
Pierre Antoine Fabre, Décréter l'image ? La XXV session du Concile de Trente
}

Paris, Les Belles Lettres, 2013, 246 p.

\section{Pascale Gruson}

\section{(2) OpenEdition}

\section{Journals}

Édition électronique

URL : http://journals.openedition.org/assr/26402

DOI : $10.4000 /$ assr.26402

ISSN : $1777-5825$

Éditeur

Éditions de l'EHESS

Édition imprimée

Date de publication : 31 décembre 2014

Pagination : 182

ISBN : 978-2-7132-2467-6

ISSN : 0335-5985

\section{Référence électronique}

Pascale Gruson, «Pierre Antoine Fabre, Décréter l'image ? La XXVe session du Concile de Trente », Archives de sciences sociales des religions [En ligne], 168 | 2014, mis en ligne le 15 avril 2015, consulté le 22 septembre 2020. URL : http://journals.openedition.org/assr/26402 ; DOI : https://doi.org/ 10.4000 /assr.26402

Ce document a été généré automatiquement le 22 septembre 2020

(C) Archives de sciences sociales des religions 


\section{Pierre Antoine Fabre, Décréter l'image ? La XXV ${ }^{\mathrm{e}}$ session du Concile de Trente}

Paris, Les Belles Lettres, 2013, 246 p.

Pascale Gruson

\section{RÉFÉRENCE}

Pierre Antoine Fabre, Décréter l'image ? La XXV ession du Concile de Trente, Paris, Les Belles Lettres, 2013, 246 p. 
1 Luther avait placé la Sola scriptura au cœur de la réforme. L'une des conséquences en fut l'encouragement à la lecture de la Bible en langue vernaculaire et le développement d'écoles paroissiales permettant l'apprentissage de la lecture, de l'écriture et du chant pour un public large.

2 Le Concile de Trente, réuni en 1543 pour tenter de rétablir l'unité de l'Église dans un monde déchiré, a donné quant à lui une place centrale à l'enseignement par l'image à la fois pieuse et édifiante. C'était là en tout cas son ultime décret, celui par lequel le Concile s'est clos en 1563. Les peintres posttridentins ont donné un éclat particulier à cette décision, étant entendu que certains d'entre eux, le Caravage en particulier, l'ont interprétée assez

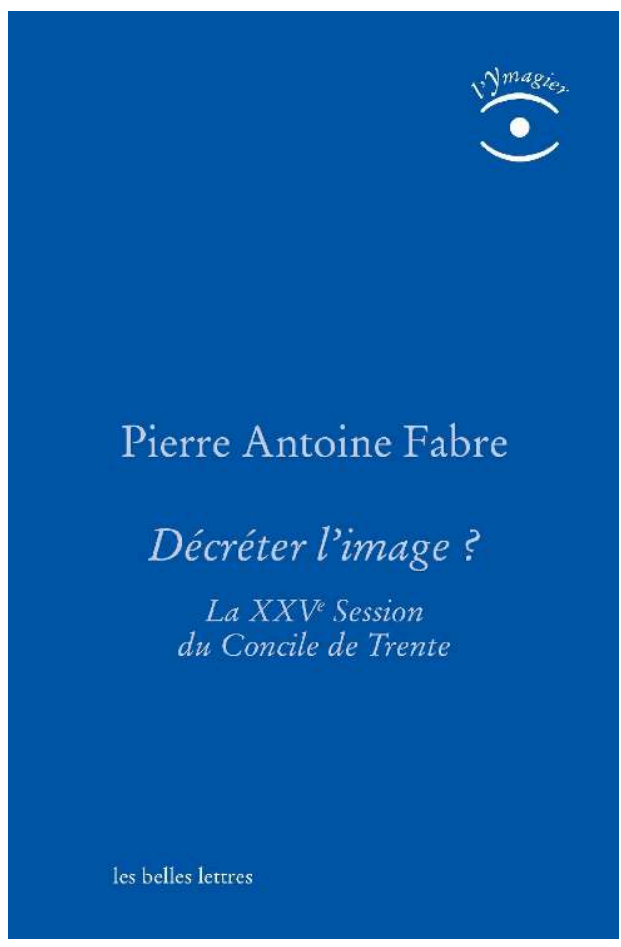
librement, voire de manière révolutionnaire. Faut-il pour autant s'en tenir à cette seule antithèse commode et un peu trop souvent évoquée ?

3 Pierre Antoine Fabre, dans une enquête serrée, propose de relire ce décret et d'approfondir l'analyse de son contexte d'écriture, dont on sait, grâce aux travaux majeurs d'Hubert Jedin et Paolo Prodi, qu'il était fort contrasté. Dès la fin du xvi ${ }^{\mathrm{e}}$ siècle, des interprétations assez divergentes en avaient déjà été données.

4 Le livre s'ouvre sur une explication de texte, celle des six points du décret. Il en résulte que ce décret n'est ni vraiment un dogme, ni même une proposition disciplinaire sur l'usage de l'image. En fait, il ne contient aucune définition claire concernant le statut de l'image pieuse et enseignante. En revanche, il comporte une décision fondamentale désignant le lieu de l'autorité légitime : l'article final stipule en effet que l'autorité de l'Église relève du pape et non des évêques. Autrement dit seul le pape peut décider du bien-fondé d'une image ; seul, il peut reconnaître, selon le commandement «Tu ne te feras pas d'image taillée à l'image de Dieu » que cette image ne représente pas une divinité. L'un des premiers historiographes du concile, le jésuite Pietro Sforza Pallavino avait immédiatement donné sens à cette décision: les images doivent apprendre et confirmer au peuple de Dieu les articles de la foi et les bienfaits de Dieu. Mais d'autres évêques ont été plus critiques.

5 Pourquoi ces précisions ont-elles de l'importance? La Réforme de Luther, qui proclame la justification par la foi et non par les œuvres, puis les aménagements que Calvin lui avait apportés, avaient dénoncé avec force cette pratique qui, dans l'Église, avait pris des proportions grandissantes et aliénantes, celle du culte des saints et de leurs reliques. Le Concile de Trente, dans sa volonté de réforme, a certainement entendu cette critique. Mais il se trouvait aussitôt placé devant un dilemme difficile, un problème quasi impossible à résoudre: comment lever l'ambiguïté du culte des reliques, tout en préservant les avantages d'une dévotion commode? La solution pouvait passer par le vecteur de l'image : en effet, si celle-ci représente une réalité, elle 
s'en distingue évidemment. L'attention aux qualités opérationnelles de l'image pouvait ouvrir à une solution d'autant plus qu'il y avait le précédent du Concile de Nicée II. Les arguments en étaient connus de bien des évêques du Concile de Trente. Pourtant l'ambiguïté n'a pas nécessairement été levée. Certes, les débats ont montré que l'image peut être comprise comme un prototype de vertus essentielles à la vie chrétienne, mais peut-on éviter le glissement du prototype vers l'hypostase ? L'image peut aussi être saisie comme une incarnation des vertus qu'elle représente. Le risque de retrouver une dévotion qui divinise l'image n'est donc pas nul, risque qui avait déjà été couru au moment de Nicée II, lorsque l'empereur Constantin fit de la représentation de sa propre image l'instrument de son pouvoir politique.

Il fallait une vigilance. Mais il fallait aussi rétablir l'unité de l'Église et d'un monde déchiré. Le pape Pie IV, qui s'était déjà opposé aux évêques en refusant la présence de représentants de la Réforme au Concile, imposa son autorité contre la leur et ne put rétablir l'unité.

7 Pierre Antoine Fabre sait montrer l'importance de ce débat dans les enjeux du Concile. Il trace aussi, outre les divers paysages politiques de ce temps, des portraits saisissants de certains pères conciliaires, notamment celui de l'espagnol Martin Perez de Ayala d'après l'autobiographie de ce dernier.

8 Un long chapitre, placé en annexe, est consacré aux débats sur le culte des images qui se déroulèrent aux colloques de Poissy et de Saint-Germain, à l'initiative de Catherine de Médicis. La Régente espérait-elle ainsi rétablir l'unité de l'Église de France ? Ces débats ont précédé, voire préparé, ceux de la $\mathrm{III}^{\mathrm{e}}$ et dernière session du Concile de Trente et en éclairent les particularités. L'une des discussions oppose Théodore de Bèze, porteur des exigences de la Réforme après la mort de Calvin, au Général des Jésuites Diego Lainez. Le premier montrait la dimension mortifère de l'image, l'autre, ses ressources de vie. Il fut impossible de décider et l'on sait que bien rapidement après ces colloques éclata, en France, la première guerre de religion.

9 À lire ce texte très tendu et souvent saisissant, on comprend bien pourquoi le monde posttridentin ne pouvait retrouver les équilibres d'antan. Et peut-être comprend-on aussi pourquoi il s'y est trouvé des Caravage. 